\title{
Fructose and NAFLD: metabolic implications and models of induction in rats ${ }^{1}$
}

\author{
Frutose e NAFLD: implicações metabólicas e modelos de indução em ratos
}

\author{
Gabriela S. F. Castro ${ }^{I}$, João F. R. CardosoI, Helio VannucchiII, Sérgio Zucoloto"I, Alceu Afonso JordãoIII \\ ${ }^{I}$ Fellow PhD degree, FMRP-USP, Ribeirao Preto-SP, Brazil. Designed the protocol, involved with technical procedures, macroscopic and \\ histopathological examinations, responsible for manuscript writing.

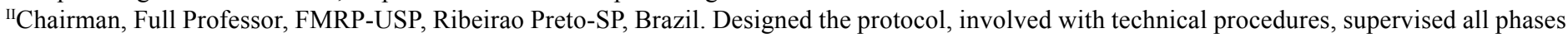 \\ of the study. \\ III Associate Professor, FMRP-USP, Ribeirao Preto-SP, Brazil. Designed the protocol, involved with technical procedures, supervised all phases of the \\ study, critical revision.
}

\begin{abstract}
PURPOSE: The increase in fructose consumption is paralleled by a higher incidence of obesity worldwide. This monosaccharide is linked to metabolic syndrome, being associated with hypertriglyceridemia, hypertension, insulin resistance and diabetes mellitus. It is metabolized principally in the liver, where it can be converted into fatty acids, which are stored in the form of triglycerides leading to NAFLD. Several models of NAFLD use diets high in simple carbohydrates. Thus, this study aimed to describe the major metabolic changes caused by excessive consumption of fructose in humans and animals and to present liver abnormalities resulting from high intakes of fructose in different periods of consumption and experimental designs in Wistar rats.

METHODS: Two groups of rats were fasted for 48 hours and reefed for 24 or 48 hours with a diet containing $63 \%$ fructose. Another group of rats was fed an diet with $63 \%$ fructose for 90 days.

RESULTS: Refeeding for 24 hours caused accumulation of large amounts of fat, compromising $100 \%$ of the hepatocytes. The amount of liver fat in animals refed for 48 hours decreased, remaining mostly in zone 2 (medium-zonal). In liver plates of Wistar rats fed $63 \%$ fructose for 45, 60 and 90 days it's possible to see that there is an increase in hepatocytes with fat accumulation according to the increased time; hepatic steatosis, however, is mild, compromising about $20 \%$ of the hepatocytes.
\end{abstract}

CONCLUSIONS: Fructose is highly lipogenic, however the induction of chronic models in NAFLD requires long periods of treatment. The acute supply for 24 or 48 hours, fasted rats can cause big changes, liver steatosis with macrovesicular in all lobular zones.

Key words: Fructose. Fatty Liver. Diet. Rats.

\section{RESUMO}

OBJETIVO: O aumento do consumo de frutose é concomitante a maior incidência mundial de obesidade. Este monossacarídeo está relacionado à Síndrome Metabólica, sendo vinculado à hipertrigliceridemia, hipertensão arterial, resistência à insulina e diabetes mellitus. É metabolizada principalmente no fígado, onde pode ser convertida em ácidos graxos, os quais serão estocados na forma de trigligérides ocasionando a esteatose hepática não alcoólica (NAFLD). Vários modelos de NAFLD utilizam dietas ricas em carboidratos simples. Desta forma, este trabalho teve como objetivos descrever as principais alterações metabólicas causadas pelo consumo excessivo de frutose em humanos e em animais e apresentar as alterações hepáticas decorrentes da alta ingestão de frutose em diferentes períodos de consumo e desenhos experimentais em ratos Wistar.

MÉTODOS: Dois grupos de ratos Wistar foram mantidos em jejum durante 48 horas e realimentados por 24 ou 48 horas com dieta contendo 63\% de frutose. Outro grupo de ratos Wistar foi alimentado com 63\% de frutose durante 90 dias.

RESULTADOS: A realimentação por 24 horas provocou acúmulo de grande quantidade de gordura. A quantidade de gordura hepática nos animais realimentados por 48 horas diminuiu, mantendo-se principalmente nas zona 2 (medio-zonal). Em fígados de ratos Wistar alimentados com $63 \%$ de frutose até 90 dias foi possível observar que há aumento de hepatócitos com acúmulo de gordura consequente ao aumento do tempo, no entanto a esteatose hepática é leve (20\%).

CONCLUSÕES: A frutose é altamente lipogênica, no entanto a indução de NAFLD em modelos crônicos necessita de longos períodos de tratamento. A oferta aguda, por 24 ou 48 horas, a ratos mantidos em jejum é capaz de ocasionar grandes mudanças hepáticas, com presença de esteatose macrovesicular em todas as zonas lobulares

Descritores: Frutose. Fígado Gorduroso. Dieta. Ratos. 


\section{Introduction}

Currently, non-alcoholic fatty liver disease (NAFLD) and nonalcoholic steatohepatitis (NASH) are related to the increasing causes of liver disease and mortality and morbidity linked to diseases of the liver ${ }^{1}$. It is estimated that the prevalence of NAFLD in developed countries reaches $10 \%$ to $24 \%$ of the population ${ }^{2}$, depending on the diagnostic criteria used ${ }^{3}$, while the worldwide prevalence of NASH reaches $2 \%$ to $3 \%$ of the general population ${ }^{3}$.

The difficulty in assessing the prevalence of NAFLD includes the absence of signs and symptoms, the low sensitivity of liver enzymes as indicators of the disease and the doubtful need of biopsy as gold standard for diagnosis ${ }^{3}$.

The NAFLD can be defined as liver accumulation of lipids, primarily in the form of triglycerides, without ingestion of significant quantities of alcohol and with the exclusion of other known causes of steatosis, as some drugs and toxins ${ }^{4}$.

The NAFLD is characterized as: type 1 - only steatosis, type 2 - steatosis plus inflammation, type 3 - steatosis plus hepatocellular injury and type 4 - steatosis plus sinusoidal fibrosis, Mallory bodies or both ${ }^{4}$. The NASH is considered the most serious form of NAFLD (types 3 and 4 ) and is also associated with cirrhosis and hepatocellular carcinoma ${ }^{4}$.

The progression of NAFLD to NASH occurs on account of damage caused by lipid peroxidation and free-radical production $^{5}$. Lipid peroxidation is accompanied by an inflammatory response and stellate cell activation, inducing fibrogenesis ${ }^{6}$.

Day and James ${ }^{7}$ proposed the "two hits" hypothesis to explain the progression of steatosis to inflammation, fibrosis and cirrhosis. The first "hit" is the steatosis, caused by imbalance between the formation and turnover of triglycerides. It is believed that insulin resistance (IR) affects the first "hit" of NAFLD as follows: it activates the adipocytokines secretion by adipocytes, alters the rate of synthesis and transport of triglycerides by hepatocytes and increases lipolysis in adipocytes that release free fatty acids (Non Esterified Fatty Acids - NEFA) in the portal circulation, exposing the liver to excessive levels of NEFAs. There is a decrease in mitochondrial function and increase in the rate of de novo synthesis and triglyceride levels. In the presence of NAFLD, other factors such as inflammation and increased oxidative stress probably lead to the progression to NASH, fibrosis and necrosis. The second "hit" is possibly caused by adipocytokines and reactive oxygen species, which activate stellate cells and increase fibrogenesis and lipid peroxidation ${ }^{8}$.

Oxidative stress inhibits the proliferation of mature hepatocytes, resulting in an increase in oval cells and progenitor cells of non-differentiated hepatocytes, the presence of both cell types being related to the progression to fibrosis ${ }^{9}$.

It is also discussed the role of factors that stimulate the synthesis of triglycerides, rather than only accumulation ${ }^{10}$, and this because NEFAs, tumor necrosis factor $-\alpha($ TNF- $\alpha$ ) and adiponectin are directly linked to the progression of NAFLD to NASH. Published studies in humans report that the increase of TNF- $\alpha$ or decrease of adiponectin are associated with increased risk of progression of NAFLD to NASH ${ }^{11}$. TNF- $\alpha$ increases the formation of reactive oxygen species, promotes apoptosis of hepatocytes and inflammation in the liver, while adiponectin diminishes hepatic triglycerides accumulation by reducing the NEFA export from adipose tissue $^{12}$.

If insults are large enough to develop cirrhosis, about 33\% of patients will die or develop morbid conditions ${ }^{8}$.

The IR has an important role for development of NASH because of participation in intracellular processes such as the loss of the inhibitory effect of insulin on $\beta$-oxidation. This mechanism induces intracellular oxidative stress. Patients with NASH have an increase in B-oxidation and in hepatic oxidative stress. These changes are also present in patients with liver fat accumulation resulting from diseases such as obesity, malnutrition, intestinal malabsorption, endocrine metabolic diseases and thyroid disorders, but only in NASH there are mitochondrial defects in the structure ${ }^{13}$.

Mitochondria are responsible for oxidative phosphorylation and B-oxidation of fatty acids, processes that are the main sources of free radicals and, together with mitochondrial disorders, play a central role in the development of $\mathrm{NASH}^{6}$. The mitochondrial abnormalities associated with NAFLD include structural damage, depletion of mitochondrial DNA, decreased activity of respiratory chain complexes and reduced mitochondrial ß-oxidation. Electron microscopy revealed that in the presence of NAFLD, the mitochondria are larger and bulkier, less in number and the mitochondrial matrix has paracrystalline inclusion and lower density ${ }^{14}$.

Moreover IR is considered as the most common risk factor for the development of NAFLD, and this one as a hepatic manifestation of the Metabolic Syndrome (MS), depending on the diagnostic criteria used ${ }^{3}$.

Independently of weight gain, MS is a great predictor for NAFLD, so important that became recognized as the hepatic manifestation of this syndrome ${ }^{8}$, since the prevalence of MS reaches $34 \%$ in the U.S. population, $53 \%$ in individuals with NAFLD and more than $88 \%$ in those with NASH ${ }^{15,16}$.

This syndrome is strongly linked to steatosis, fibrosis and cirrhosis in obese adults in part for glucose intolerance and IR. Numerous studies have shown that obesity, type 2 diabetes mellitus, dyslipidemia, hypertension and IR are associated with NAFLD. It is also associated with reduced insulin sensitivity in liver and fat tissue of liver, and throughout the body, increasing rate of gluconeogenesis and reduced fatty acid oxidation. However, there is still no consensus on whether the IR is cause or consequence of steatosis ${ }^{8}$.

Many patients with NAFLD are asymptomatic. In the absence of cirrhosis, hepatomegaly is the only physical finding in most patients, present in more than $75 \%$ of cases $^{3}$. The use of liver biopsy for the diagnosis of NAFLD is controversial. Usual markers of NAFLD are alanine aminotransferase (ALT) and aspartate aminotransferase (AST), elevated levels of these being considered as a consequence of liver damage, fatty infiltration and inflammation. Serum levels of these enzymes are related to multiple components of $\mathrm{MS}^{8}$.

Several studies have demonstrated the induction of NAFLD in rats by diets with large amounts of simple carbohydrates ${ }^{17,18}$. However, few are focused on dietary manipulation for effective reversal of metabolic damage generated by these diets ${ }^{17}$. 
Consumption of simple carbohydrates such as sucrose and fructose has increased steadily over the last 20 years ${ }^{17}$. The excess of glucose or fructose causes the synthesis of triacylglycerols that will accumulate in the liver. This accumulation is the cause of NAFLD ${ }^{1,5}$.

Rats fed a diet high in simple carbohydrates (SC) developed dyslipidemia, weight gain, visceral adiposity and reduced insulin sensitivity ${ }^{17}$. Axen et al. ${ }^{19}$ also reported higher levels of triglycerides in obese mice fed with SC compared to those fed a high-fat diet and, similarly, another study indicated that by replacing fat with carbohydrates the diet contributes to weight gain $^{20}$.

Ackerman et al. ${ }^{1}$ reported the inuction of NAFLD in rats fed by fructose as carbohydrate source. The model of experimental induction of NAFLD through diets high in fructose is well studied, being able to cause hypertension, hypertriglyceridemia, hyperinsulinemia and IR in rats ${ }^{21}$. Supplementation with fructose for six days in healthy men caused an increased fasting glucose and endogenous glucose production ${ }^{22}$. Fructose may be the critical component associated with the risk of obesity and heart disease, and clinical studies confirm that sucrose, and fructose in particular, can induce weight gain and MS features ${ }^{23}$.

\section{Fructose consumption}

The estimated consumption of fructose by the population is difficult to achieve because their consumption is not measured in most surveys or databases ${ }^{24}$. According to the International Sugar Organization (Sugar Year Book. London, 2008), South America and Oceania are the biggest consumers of sugar ${ }^{24}$.

In the U.S. population, fructose consumption before 1900 came mainly from fruit and vegetable intake of about $15 \mathrm{~g} /$ day; consumption increased for $24 \mathrm{~g} /$ day in the period before World War II; around 1977 it reached $37 \mathrm{~g} /$ day and in $199455 \mathrm{~g} /$ day $^{15}$. Tappy and Lee noted in a review that according to the Third National Health and Nutrition Examination Survey, currently it is estimated that fructose consumption by teenagers reaches $72.8 \mathrm{~g} /$ day $^{24}$.

The large growth in consumption of fructose is due in great part to the development of techniques that allowed the extraction of starch from corn, its hydrolysis into glucose and the enzymatic isomerization of glucose to fructose, thereby producing large-scale syrup corn (High Fructose Corn Syrup - HFCS) after 1960 's ${ }^{25}$.

The HFCS presents good stability in acidified food and drink; being liquid, its transport and storage are easier than those of sucrose, and being derived from corn, HFCS has become one of the ingredients most used by food industry ${ }^{26}$. It consists of approximately $55 \%$ fructose and $45 \%$ glucose. It is widely used in soft drinks and processed juices. The largest consumers of fructose, according to The Third National Health and Nutrition Examination Survey ${ }^{26}$, are adolescents and young adults.

It is important to consider that the increased consumption of free fructose was accompanied by a decrease in consumption of sucrose, in which fructose is linked to glucose $\mathrm{e}^{24}$. Although Bray et al. ${ }^{27}$ proposed that the increase in obesity was directly associated with increased consumption of HFCS, as they both grew in the period 1960 to 2000 , we must consider that during this same period other factors also influenced the increase in obesity, such as increased consumption of total calories and fat ${ }^{26}$.

Studies in humans with increased consumption of fructose showed weight gain and significant increase in triglycerides, systolic blood pressure and IR. Most of the diets provided 400 to $800 \mathrm{kcal} /$ day of fructose, values among the highest rates consumed in the United States ${ }^{23}$.

\section{Fructose metabolism}

Fructose is a monosaccharide with the same chemical formula as glucose, the difference lying in its structure. It possesses in its second carbon a ketone group ${ }^{28}$. Figure 1 illustrates the structural formula of glucose and fructose.

Its metabolism differs from glucose's by not requiring insulin to enter the cell ${ }^{28}$. Absorption occurs via a specific transporter present in intestinal cells, the GLUT5, which increases in quantity according to levels of dietary fructose; in the liver its entrance occurs with GLUT2 transporter, being this transport by facilitated diffusion and independent of sodium. This transporter has high affinity on account of its chemical structure, existing competition with sorbitol due to their similarity. The liver retains at least $50 \%$ of the ingested fructose diet, and there fructose will be phosphorylated by frutoquinase into fructose-1-phosphate, which is then converted into glyceraldehyde and dihydroxyacetone phosphate. Glyceraldehyde will be later converted into glyceraldehyde-3-phosphate and participate in the de novo synthesis of fatty acids. Another portion of these substrates will be converted into lactate and will be part of neogluconeogenesis ${ }^{28}$.

Fructose doesn't need phosphofructokinase to be metabolized, differently from glucose, which undergoes negative regulation by citrate and ATP, because they inhibit the enzyme ${ }^{28}$. Fructokinase is the first enzyme that converts fructose, producing fructose-1-phosphate, which will be converted to glyceraldehyde and dihydroxyacetone phosphate by ketosis-1-phosphate aldolase ${ }^{29}$.

There are two sources of fructose to the body, the exogenous, supplied by the diet, and the endogenous, made from glucose via aldose reductase. The offer of fructose by each of these pathways depends on factors such as exogenous availability, transport rate and activity of aldose reductase and sorbitol dehydrogenase. These two enzymes constitute the metabolic pathway of polyols, responsible for the formation of fructose in the tissues; this formation is activated by hyperglycemia and forms fructose from sorbitol in the corneas, kidneys and peripheral nerves, for at these the excess glucose is converted to sorbitol by aldose reductase, which generates fructose by sorbitol dehydrogenase ${ }^{29}$.

The fructose inability to stimulate insulin and leptin acutely and to inhibit ghrelin is a factor that admittedly affects the control of satiety in the central nervous system ${ }^{23}$. It also seems to decrease the basal metabolic rate, because mice that drank fructose water gained more weight than those who ate the same calories, but from $\operatorname{starch}^{23}$.

\section{Fructose and NAFLD}

Fructose has been appointed as a factor linked to the increase of obesity in recent decades ${ }^{24}$. Its intake is also linked to 
the severity of nonalcoholic fatty liver disease, being visible that NAFLD patients with larger fructose consumption had increased liver inflammation and fibrosis ${ }^{30}$. High-fructose diets constitute an experimental model for NAFLD. The animals begin to display characteristics of MS, including insulin resistance, hyperinsulinemia, hypertriglyceridemia and hypertension ${ }^{28}$.

In animals, the induction of non-alcoholic fatty liver disease through the glut of simple carbohydrates such as sucrose and fructose, requires more time of experiment, compared to other models. With a shorter time it is already possible to see features of Metabolic Syndrome (MS) as the increase in dyslipidemia, insulin secretion and plasma free fatty acids, accumulation of triglycerides in the liver and enlarged adiposity ${ }^{31}$. On the other hand, some studies have reported the use of such diets for periods of up to 40 weeks. When offered for a short time, about five weeks, it constitutes a model to analyze the forms of treatment of MS, since it is possible to observe some of its constituents, such as dyslipidemia and increased body fat ${ }^{32}$.

\section{Methods}

This study was approved by the Ethics Committee on Animal Research of the Faculty of Medicine of Ribeirão Preto. We used male Wistar rats from the Animal Service Campus USP - Ribeirão Preto and subsequently maintained in the Animal Department of Clinical Medicine, Faculty of Medicine of Ribeirão Preto, USP. The light-dark regime was kept constant at 12 to 12 hours and the temperature maintained at $24 \pm 2^{\circ} \mathrm{C}$.

All animals were handled in accordance with the recommendations of "The Guide for the Care and Use of Laboratory Animals" prepared by the "National Academy of Sciences" and published by "National Institutes of Health" (NIH publication, 1985, 140p).

The diets offered were prepared in accordance with what recommended the American Institute of Nutrition ${ }^{33}$, with changing of the carbohydrate source, replacing starch and sucrose by fructose (Figure 1).<smiles>O=CC(O)C(O)C(O)C(O)CO</smiles><smiles>O=C(CO)C(O)C(O)C(O)CO</smiles>

\section{D-glicose}

\section{D-frutose}

For histological analysis, fragments of liver tissue were cut, being kept for 24 hours in a solution of $10 \%$ buffered formaldehyde. Shortly thereafter, this solution was replaced with $70 \%$ alcohol. After this step, the livers were immersed in paraffin and then cut with a thickness of $4 \mathrm{~m}$ and stained with hematoxylineosin, in order to semi-quantitatively assess hepatic steatosis, which was classified as crosses, according to Oh et al. ${ }^{34}$, with some modifications. The degree of steatosis was associated with morphological location (zone 1, 2 and 3) 0 (0\%) 1-25\% (1: little present in zone 3$), 25-50 \%$ (2: zone 3$) ; 50-75 \%$ (3: zones 2 and 3$)$ and $75-100 \%$ (4: Zone 1,2 and 3$)$.

\section{Results and Discussion}

Figure 2 shows liver plates of Wistar rats that were fasted for 48 hours and refed for 24 (Figure 2b) and 48 hours (Figure 2c) with diet containing $63 \%$ fructose.

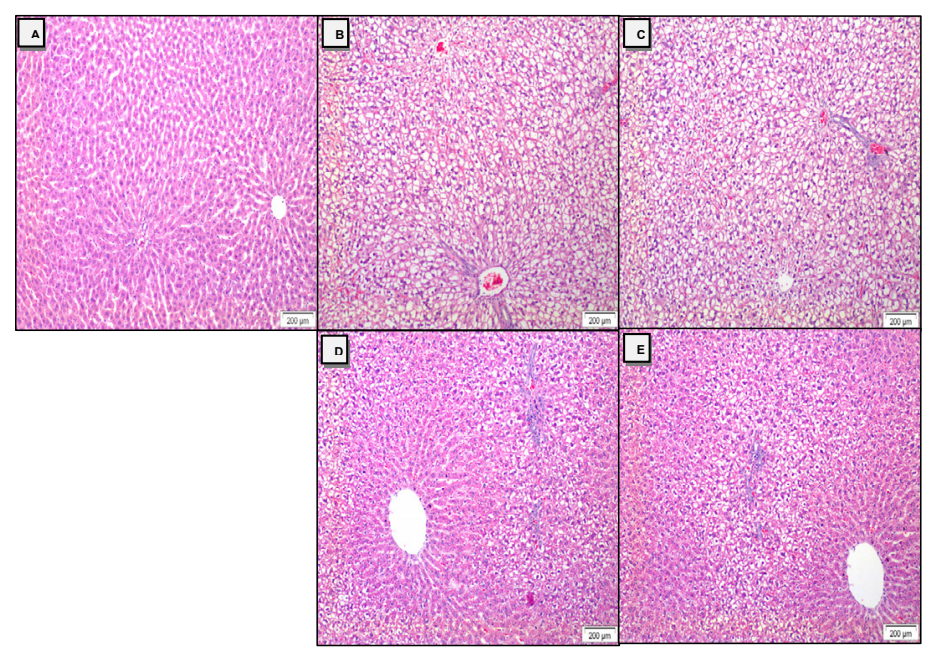

FIGURE 2 - Microphotographs of normal liver tissue (A) and animals fasted for 48 hours and refed with high-fructose diet for 24 hours (B and C) and $48 \mathrm{~h}$ (D and E). H \& E, 10x

Refeeding for 24 hours caused accumulation of large amounts of fat, compromising $100 \%$ of the hepatocytes. The amount of liver fat in animals refed for 48 hours decreased, remaining mostly in zone 2 (medium-zonal). Figure 3 shows liver plates of Wistar rats fed 63\% fructose for 45, 60 and 90 days. It's possible to see that there is an increase in hepatocytes with fat accumulation according to the increased time; hepatic steatosis, however, is mild, compromising about $20 \%$ of the hepatocytes.

FIGURE 1 - Structural formula of D-glucose and D-fructose 


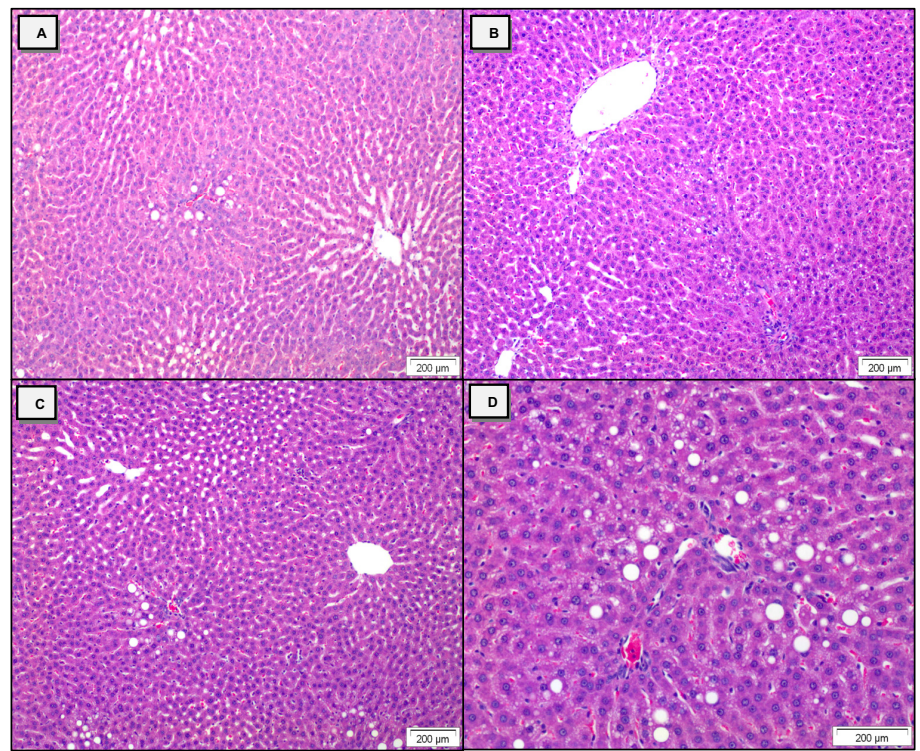

FIGURE 3 - Microphotograps of liver tissue showing histological aspects of animals refed with high-fructose diet for 45 days (A), 60 days (B) and 90 days (C and D). H\&E, 10x (A, B and C) and 20x (D).

Refeeding with high-fructose diet caused a large accumulation of liver triacylglycerols; however, with the increase of the offer period of this diet, there were adaptive changes and steatosis has not presented itself so markedly, although it is still significantly present. In another study that evaluated the refeeding with 16 grams of carbohydrates (starch and sucrose in the same ratio) after 24 hours of fasting it was observed increase in liver volume, though these animals have shown a lower content of triglycerides compared to group refed with high-fat $\operatorname{diet}^{35}$.

Delzenne et al. ${ }^{36}$ also described the accumulation of hepatic fat in animals refed for 6 hours on high carbohydrate diet (40\% sucrose and $40 \%$ starch) with the presence of mild steatosis microvesicular mainly in zone I, while the macrovesicular steatosis extended for the three zones.

The larger formation of acetyl-CoA by both fructose and sucrose, when they are offered in excess, causes a higher formation of fatty acids that will be stored in the form of triglycerides in the liver.

A study comparing the supply of sucrose and the supply of glucose and fructose showed that both diets were able to cause the MS, differing in the fact that glucose plus fructose induced higher formation of uric acid ${ }^{37}$. This is because fructose has the particularity of inducing higher formation of uric acid, compared to glucose and sucrose, however for this to occur in rats it is required a treatment with oxonic acid to uricase inhibition, an enzyme present in rats capable of converting uric acid into allantoin $^{37}$.

The fructose offered in diet to adult Wistar rats for 4 weeks, with 90 days of life, is more effective in producing the characteristics of MS compared to rats with 28 days of life, fed for 8 weeks. In adult animals there was an increase of fat liver, white adipose tissue, total cholesterol, HDL, LDL, triglycerides and serum insulin. Also offering $60 \%$ fructose in the diet was more effective than offering $10 \%$ fructose in water ${ }^{32}$.

\section{Conclusions}

The oversupply of fructose in rats facilitates the appearance of several features of the Metabolic Syndrome. However, the establishment of NAFLD requires more time to experiment. This work was the first to show the effects on liver morphology of fructose refeeding in rats maintained in fasting for long periods. It's interesting to highlight that this model can be widely used in the search for metabolic targets for counteracting the effects of excess fructose.

\section{References}

1. Ackerman Z, Oron-Herman M, Grozovski M, Rosenthal T, Pappo O, Link G, Sela BA. Fructose-induced fatty liver disease: hepatic effects of blood pressure and plasma triglyceride reduction. Hypertension. 2005;45:1012-8.

2. Delarue J, LeFoll C, Corporeau C, Lucas D. N-3 long chain polyunsaturated fatty acids: a nutritional tool to prevent insulin resistance associated to type 2 diabetes and obesity? Reprod Nutr Dev. 2004;44:289-99.

3. Parekh S, Anania FA. Abnormal lipid and glucose metabolism in obesity: implications for nonalcoholic fatty liver disease. Gastroenterology. 2007;132:2191-207.

4. Zivkovic AM, German JB, Sanyal AJ. Comparative review of diets for the metabolic syndrome: Implications for nonalcoholic fatty liver disease. Am J Clin Nutr. 2007;86:285-300.

5. Bradbury MW. Lipid metabolism and liver inflammation. I. Hepatic fatty acid uptake: possible role in steatosis. Am J Physiol Gastrointest Liver Physiol. 2006;290:G194-8.

6. Oliveira CP, Coelho AM, Barber HV, Lima VM, Soriano F, Ribeiro C, Molan NA, Alves VA, Souza HP, Machado MC, Carrilho FJ. Liver mitochondrial dysfunction and oxidative stress in the pathogenesis of experimental nonalcoholic fatty liver disease. Braz J Med Biol Res. 2006;39:189-94.

7. Day CP, James OF. Steatohepatitis: a tale of two "hits"? Gastroenterology. 1998;114:842-5.

8. Rector RS, Thyfault JP, Wei Y, Ibdah JA. Non-alcoholic fatty liver disease and the metabolic syndrome: an update. World J Gastroenterol. 2008; 14:185-92.

9. Dowman JK, Tomlinson JW, Newsome PN. Pathogenesis of non-alcoholic fatty liver disease. QJM. 2010;103:71-83.

10. Lam TK, van de Werve G, Giacca A. Free fatty acids increase basal hepatic glucose production and induce hepatic insulin resistance at different sites. Am J Physiol Endocrinol Metab. 2003;284:E281-90.

11. Hui JM, Hodge A, Farrell GC, Kench JG, Kriketos A, George J. Beyond insulin resistance in NASH: TNF-alpha or adiponectin? Hepatology. 2004;40:46-54.

12. Choi SS, Diehl AM. Hepatic triglyceride synthesis and nonalcoholic fatty liver disease. Curr Opin Lipidol. 2008;19:295-300.

13. Portincasa P, Grattagliano I, Palmieri VO, Palasciano G. Nonalcoholic steatohepatitis: recent advances from experimental models to clinical management. Clin Biochem. 2005;38:203-17.

14. Wei Y, Rector RS, Thyfault JP, Ibdah JA. Nonalcoholic fatty liver disease and mitochondrial dysfunction. World J Gastroenterol. 2008;14:193-9.

15. Lim JS, Mietus-Snyder M, Valente A, Schwarz JM, Lustig RH. The role of fructose in the pathogenesis of NAFLD and the metabolic syndrome. Nat Rev Gastroenterol Hepatol. 2010;7:251-64.

16. Marchesini G, Bugianesi E, Forlani G, Cerrelli F, Lenzi M, Manini R, Natale S, Vanni E, Villanova N, Melchionda N, Rizzetto M. Nonalcoholic fatty liver, steatohepatitis, and the metabolic syndrome. Hepatology. 2003;37:917-23. 
17. Fortino MA, Lombardo YB, Chicco A. The Reduction of dietary sucrose improves dyslipidemia, adiposity, and insulin secretion in an insulin-resistant rat model. Nutrition. 2007;23:489-97.

18. Sivakumar AS, Anuradha CV. Effect of galangin supplementation on oxidative damage and inflammatory changes in fructose-fed rat liver. Chem Biol Interact. 2011;193:141-8.

19. Axen KV, Axen K. Very low-carbohydrate versus isocaloric high-carbohydrate diet in dietary obese rats. Obesity (Silver Spring). 2006; 14:1344-52.

20. Gamba CA, Friedman SM, Rodriguez PN, Macri EV, Vacas MI, Lifshitz F. Metabolic status in growing rats fed isocaloric diets with increased carbohydrate-to-fat ratio. Nutrition. 2005;21:249-54.

21. Sanchez-Lozada LG, Tapia E, Jimenez A, Bautista P, Cristobal M, Nepomuceno T, Soto V, Avila-Casado C, Nakagawa T, Johnson RJ, Herrera-Acosta J, Franco M. Fructose-induced metabolic syndrome is associated with glomerular hypertension and renal microvascular damage in rats. Am J Physiol Renal Physiol. 2007;292:F423-9.

22. Faeh D, Minehira K, Schwarz JM, Periasamy R, Park S, Tappy L. Effect of fructose overfeeding and fish oil administration on hepatic de novo lipogenesis and insulin sensitivity in healthy men. Diabetes. 2005;54:1907-13.

23. Johnson RJ, Segal MS, Sautin Y, Nakagawa T, Feig DI, Kang DH, Gersch MS, Benner S, Sanchez-Lozada LG. Potential role of sugar (fructose) in the epidemic of hypertension, obesity and the metabolic syndrome, diabetes, kidney disease, and cardiovascular disease. Am J Clin Nutr. 2007;86:899-906.

24. Tappy L, Le KA. Metabolic effects of fructose and the worldwide increase in obesity. Physiol Rev. 2010;90:23-46.

25. Marshall RO, Kooi ER. Enzymatic conversion of D-glucose to D-fructose. Science. 1957;125:648-9.

26. White JS. Straight talk about high-fructose corn syrup: what it is and what it ain't. Am J Clin Nutr. 2008;88:1716S-21S.

27. Bray GA, Nielsen SJ, Popkin BM. Consumption of high-fructose corn syrup in beverages may play a role in the epidemic of obesity. Am J Clin Nutr. 2004;79:537-43.
28. Tran LT, Yuen VG, McNeill JH. The fructose-fed rat: a review on the mechanisms of fructose-induced insulin resistance and hypertension. Mol Cell Biochem. 2009;332:145-59.

29. Schalkwijk CG, Stehouwer CD, van Hinsbergh VW. Fructose-mediated non-enzymatic glycation: sweet coupling or bad modification. Diabetes Metab Res Rev. 2004;20:369-82.

30. Abdelmalek MF, Suzuki A, Guy C, Unalp-Arida A, Colvin R, Johnson RJ, Diehl AM. Increased fructose consumption is associated with fibrosis severity in patients with nonalcoholic fatty liver disease. Hepatology. 2010;51:1961-71.

31. Lombardo YB, Chicco AG. Effects of dietary polyunsaturated n-3 fatty acids on dyslipidemia and insulin resistance in rodents and humans. A review. J Nutr Biochem. 2006;17:1-13.

32. de Moura RF, Ribeiro C, de Oliveira JA, Stevanato E, de Mello MA. Metabolic syndrome signs in Wistar rats submitted to different high-fructose ingestion protocols. Br J Nutr. 2009;101:1178-84.

33. Reeves PG, Nielsen FH, Fahey GC, Jr. AIN-93 purified diets for laboratory rodents: final report of the American Institute of Nutrition ad hoc writing committee on the reformulation of the AIN-76A rodent diet. J Nutr. 1993;123:1939-51.

34. Oh SI, Kim CI, Chun HJ, Park SC. Chronic ethanol consumption affects glutathione status in rat liver. J Nutr. 1998;128:758-63.

35. Sanchez J, Palou A, Pico C. Response to carbohydrate and fat refeeding in the expression of genes involved in nutrient partitioning and metabolism: striking effects on fibroblast growth factor-21 induction. Endocrinology. 2009;150:5341-50.

36. Delzenne NM, Hernaux NA, Taper HS. A new model of acute liver steatosis induced in rats by fasting followed by refeeding a high carbohydrate-fat free diet. Biochemical and morphological analysis. J Hepatol. 1997;26:880-5.

37. Sanchez-Lozada LG, Mu W, Roncal C, Sautin YY, Abdelmalek M, Reungjui S, Le M, Nakagawa T, Lan HY, Yu X, Johnson RJ. Comparison of free fructose and glucose to sucrose in the ability to cause fatty liver. Eur J Nutr. 2010;49:1-9.

\section{Correspondence:}

Alceu Afonso Jordão

Faculdade de Medicina de Ribeirão Preto

Laboratório de Nutrição e Metabolismo - Anexo A

Av. Bandeirantes, 3900

Campus Universitário Monte Alegre

14048-900 Ribeirão Preto - SP Brasil

Tel/Fax: (55 16)3602-4564

alceu@,fmrp.usp.br

Conflict of interest: none

Financial source: $\mathrm{CNPq}$

${ }^{1}$ Research performed at Laboratory of Nutrition and Metabolism, Faculty of Medicine of Ribeirao Preto, University of Sao Paulo (FMRP-USP), Ribeirao Preto-SP, Brazil.

Presented at the XII National Congress on Experimental Surgery of the Brazilian Society for Development of Research in Surgery-SOBRADPEC, 2011 October 26-29 Ribeirao Preto-SP, Brazil. 